\title{
Modelling the transport success of anchovy Engraulis encrasicolus eggs and larvae in the southern Benguela: the effect of spatio-temporal spawning patterns
}

\author{
Jenny Huggett ${ }^{1, *}$, Pierre Fréon ${ }^{1,2}$, Christian Mullon ${ }^{2,3}$, Pierrick Penven ${ }^{2}$ \\ ${ }^{1}$ Marine and Coastal Management, Private Bag X2, Roggebaai 8012, South Africa \\ ${ }^{2}$ Institut de Recherche pour le Développement, 213, rue La Fayette, 75480 Paris, France \\ ${ }^{3}$ Department of Oceanography, University of Cape Town, Private Bag, Rondebosch 7701, Cape Town, South Africa
}

\begin{abstract}
Recruitment success of anchovy Engraulis encrasicolus in the southern Benguela is thought to depend largely on the passive transport of eggs and larvae from their warm-water spawning area, located in the southern part of their distribution range (Agulhas Bank), to their cold-water nursery grounds located $500 \mathrm{~km}$ away on the west coast of South Africa. In order to test this hypothesis, the output of a 3D hydrodynamic model was coupled to a particle-tracking model, allowing the quantification of different factors such as the timing and precise location of spawning activity, the frequency of spawning activity within a month, the level of aggregation of the spawning stock, and the interannual variability of transport due to mesoscale processes. Results from the model indicate that spawning season and area have a major effect on transport success. The most favourable period for spawning was September to March, peaking in November, and the western Agulhas Bank was the most favourable spawning area. A low success rate of passive transport to the core inshore nursery area in the model suggests that additional processes such as swimming or advection are required for larvae to reach this area. In general, there was good agreement between observed spawning patterns and the optimal temporal and spatial strata where particle transport was most successful, suggesting that the spawning strategy of anchovy is mainly the result of an adaptation to the circulation patterns in the region. Nonetheless, some discrepancies were observed between the success of transport and actual spawning patterns, and temperature may also be an important factor to take into consideration to fully explain how this originally temperate species is able to survive in an area of highly contrasting temperatures.
\end{abstract}

KEY WORDS: Individual-based model - Transport success · Anchovy · Ichthyoplankton · Recruitment $\cdot$ Reproductive strategy $\cdot$ Southern Benguela $\cdot$ Engraulis encrasicolus

Resale or republication not permitted without written consent of the publisher

\section{INTRODUCTION}

Populations of small pelagic clupeoid fishes such as anchovies and sardines, which inhabit coastal upwelling systems, have undergone large fluctuations in abundance over the last century (Lluch-Belda et al. 1989, 1992, Schwartzlose et al. 1999). Whereas most of the observed rapid declines in abundance may be associated with intensive fishing, evidence from deposits of fish scales in sediments off several upwelling areas (Shackleton 1987, Baumgartner et al. 1992) suggests that extreme fluctuations in population sizes of these fishes occurred long before the emergence of large-scale fishing. This points to environmental or biotic factors being largely responsible for such fluctuations.

In the southern Benguela, the European anchovy Engraulis encrasicolus (Linnaeus 1758), formerly called E. capensis (Gilchrist 1913), and the sardine Sardinops sagax (Jenys 1842) comprise more than $80 \%$ of the 
total purse-seine fishery catch (Barange et al. 1999). Catches during the 1950s and early 1960s were dominated by adult sardine, peaking at $\sim 400000 \mathrm{t}$ in 1961-62, but declined to <100 000 t by 1967 (Verheye et al. 1998). This collapse was followed by a rapid increase in catches of anchovy, which replaced sardine as the dominant species during the 1970s and 1980s (Crawford et al. 1987). In addition to these decadalscale fluctuations in abundance, direct acoustic estimates of pelagic fish abundance since 1984 (Hampton 1987, 1992, Barange et al. 1999) have indicated considerable annual variability in recruitment of both sardine and anchovy, particularly the latter (Fig. 1). Estimated variations in anchovy recruitment were 5 -fold during the period 1984 to 1999 and increased to nearly 20 -fold after $2 \mathrm{yr}$ of exceptional recruitment in 2000 and 2001.

Recruitment of pelagic fish is the net result of a continuous series of life-cycle events, but most of the variability in natural mortality is thought to occur during the early stages of development and to relate to environmental factors (Bakun 1996). However, recruitment predictions made from empirical relationships between environmental factors and abundance have failed in many instances, in the Benguela as well as in other regions (Myers 1998), emphasising the importance of understanding the underlying processes. A number of theories addressing likely sources of egg and larval mortality, and hence recruitment success, have been developed over the previous century; these have been comprehensively reviewed by Anderson (1988) and Cole \& McGlade (1998). It is now generally recognised that no single factor or event is responsible for deter-

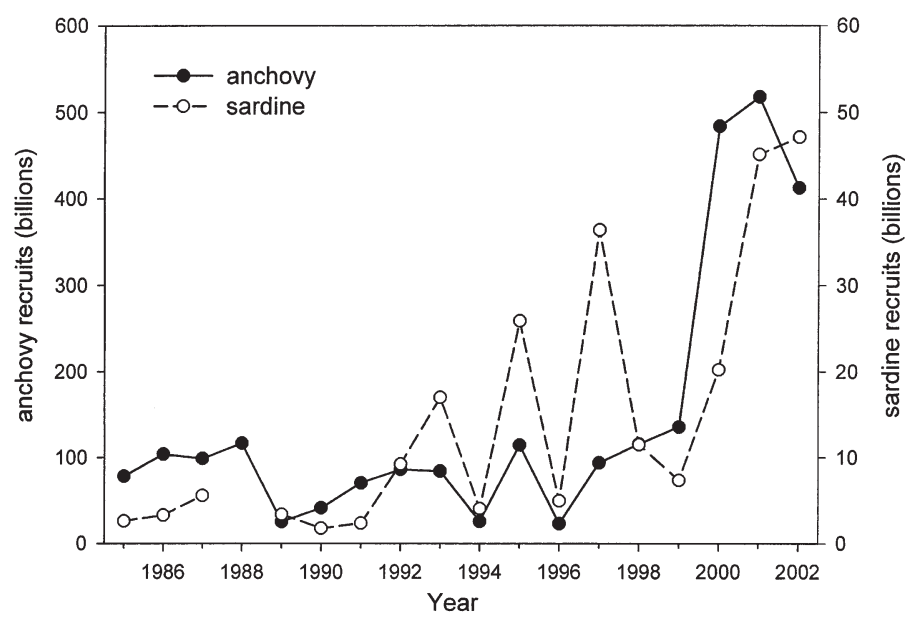

Fig. 1. Engraulis encrasicolus and Sardinops sagax. Numbers of anchovy and sardine recruits (billions) in the southern Benguela estimated from annual winter (May-June) acoustic pelagic recruitment surveys over the period 1985 to 2002 (Hampton 1992, Barange et al. 1999, updated by J. Coetzee pers. comm.) mining year-class strength, and concepts that integrate a number of processes influencing recruitment are gaining prominence, such as the optimal environmental window (OEW) theory of Cury \& Roy (1989) and Bakun's (1996) triad hypothesis, which suggests that enrichment, concentration, and retention are important processes influencing the recruitment success of coastal pelagic fishes.

Previous attempts to forecast anchovy recruitment in the southern Benguela have mainly followed 2 different approaches: the establishment of empirical relationships between environmental or biological variables and recruitment strength (Boyd et al. 1998, Richardson et al. 1998, Roy et al. 2001), and the development of expert systems (Korrûbel et al. 1998, Painting \& Korrûbel 1998, Painting et al. 1998). Some of the environmental relationships were conflicting, and none withstood the 'test of time', although the expert system approach shows considerable promise.

The unreliability of empirical relationships is not surprising considering that different variables, or combinations of variables, may determine recruitment success from year to year (Hutchings et al. 1998). The complexity of the 'recruitment problem' has led to an increasing realisation of the need for new techniques that are able to explore the complex ecological processes affecting the recruitment of pelagic fishes. A common way of representing the early life-history stages is by considering eggs and larvae as passive particles confronting environmental conditions provided by the output of hydrodynamic models. This Lagrangian approach has also been used for zooplankton (e.g. Miller et al. 1998) and fishes (e.g. Heath \& Gallego 1997). Adding biological properties to these particles results in so-called individual-based models (IBMs), which have recently emerged as a useful tool for describing interactions between individuals displaying different behaviours within a population, and their environment. IBMs permit the spatial representation and integration of environmental, ecological and biological data (DeAngelis \& Gross 1992, Tyler \& Rose 1994, Letcher et al. 1996, Grimm 1999, Werner et al. 2001).

The life history of anchovy in the southern Benguela incorporates distinct spawning, transport and nursery regions, and is summarised in Hutchings \& Boyd (1992) and Hutchings et al. (1998). Adult anchovy spawn serially during spring and summer (September to March) on the Agulhas Bank (Fig. 2), mainly in the western region, which contains the bulk of the spawner population. Eggs and larvae are rapidly transported to the west coast nursery area by frontal jet currents (typically 0.5 to $0.75 \mathrm{~m} \mathrm{~s}^{-1}$, Boyd et al. 1992), but losses of spawning products are likely to result from offshore transport via filaments, eddies, and Ekman transport, 


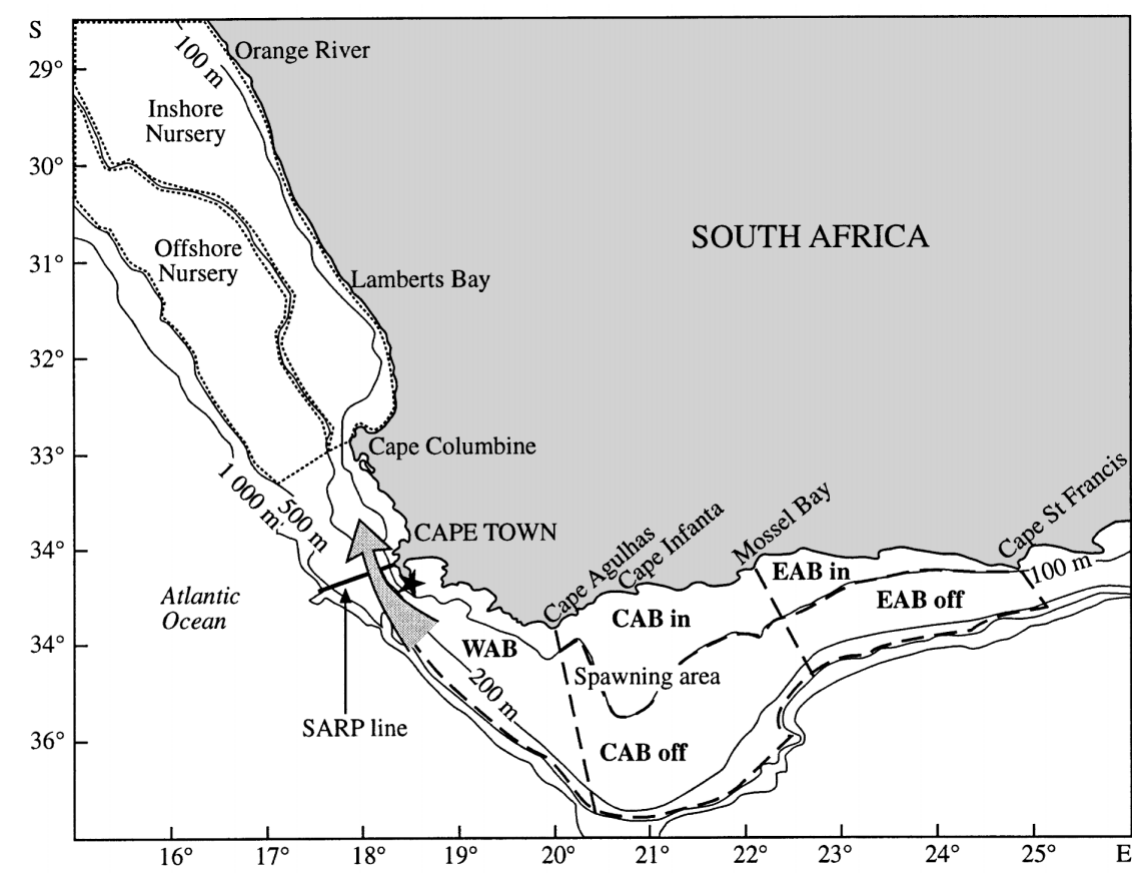

Fig. 2. Map showing the 5 Engraulis encrasicolus spawning areas on the Agulhas Bank (indicated by dashed lines) and the 2 nursery areas on the west coast as used in the model (indicated by dotted lines), as well as locations mentioned in the text: western Agulhas Bank (WAB), central Agulhas Bank (CAB), and eastern Agulhas Bank (EAB). The arrow indicates the approximate location of the shelf-edge jet current, the star indicates the location of Cape Point, and the SARP monitoring line is represented by the solid line to the NW of Cape Point certainties pertinent to the earlier developmental stages have been resolved, such as vertical distribution and buoyancy of the eggs, mortality and growth.

Four hypotheses relating to different spatio-temporal scales of spawning are tested in the present study: that (1) the area and/or month of spawning affects successful transport from the spawning grounds to the nursery region, (2) spawning patchiness within each area significantly affects transport success, (3) spawning frequency within each month significantly affects transport success, and (4) the modelled current regime facilitates passive transport of spawning products directly into the core (inshore) nursery area, and not only into the adjacent offshore region. Finally, the model is used to improve our understanding of the particular adaptive reproductive strategy of anchovy in the Benguela ecosystem by simulating alternative strategies not observed in nature, such as spawning during winter. which are known to be important in the region (Shannon et al. 1996, Hutchings et al. 1998). Successfully transported larvae are thought to migrate across the wide shelf to a nursery region close inshore along the west coast. Here the juvenile fish form the basis of a valuable reduction fishery during winter, before moving southwards towards the Agulhas Bank to spawn at 1 yr of age.

Because the spawning and nursery areas are about $500 \mathrm{~km}$ apart, transport is likely to be a key factor in the success of anchovy recruitment in the southern Benguela. A simplified simulation model of egg and larval transport by Shannon et al. (1996) showed that fluctuations in passive transport (e.g. advective losses) of young anchovy may account for a substantial proportion of year-class variability.

The aim of the present study is to use a particletracking model to investigate the success of different spatio-temporal spawning strategies on the Agulhas Bank in relation to the passive transport of eggs and larvae to the west coast nursery area. This model was designed as part of a proper IBM, in order to allow testing of other factors influencing recruitment success in future investigations, using a step-by-step approach of adding increasing complexity to the model once un-

\section{METHODS}

The hydrodynamic model. The particle-tracking model uses the output of a 3D hydrodynamic model of circulation in the southern Benguela, known as Plume (Penven et al. 2001a). The ocean model is the regional ocean modelling system (ROMS; Haidvogel et al. 2000). It solves the free surface, primitive equations in an earthcentred rotating environment, based on the Boussinesq approximation and hydrostatic vertical momentum balance. ROMS is discretised in coastline- and terrainfollowing curvilinear coordinates. A third-order, upstream-biased advection scheme implemented in ROMS allows the generation of steep gradients (Shchepetkin \& McWilliams 1998), and explicit lateral viscosity is null everywhere except near the open boundaries. A non-local, K-profile planetary (KPP) boundary layer scheme (Large et al. 1994) parameterises the unresolved physical vertical subgrid-scale processes.

The Plume grid is pie-shaped, curving around the SW South African coastline from 28 to $40^{\circ} \mathrm{S}$ and from 10 to $24^{\circ} \mathrm{E}$ (Fig. 3). The horizontal resolution ranges from $9 \mathrm{~km}$ at the coast to $16 \mathrm{~km}$ offshore. A lower resolution grid (18 $\mathrm{km}$ at the coast) was used to test the sensitivity of the model to horizontal resolution. Although 
the low-resolution configuration is able to simulate the main features of the regional circulation, the highresolution grid is about 2 times finer than the first baroclinic Rossby radius of deformation (ca. 20 to $30 \mathrm{~km}$ in this area), and thus totally resolves the dominant scale of the most unstable waves. Hence, our high-resolution solution differs from the coarser one mainly by the level of mesoscale activity that develops during the simulation (Penven et al. 2001a). At this high resolution, the baroclinic time step was $1800 \mathrm{~s}$ and the barotropic time step was $38 \mathrm{~s}$.

Twenty vertical levels preserve a high resolution near the surface. Since ROMS uses terrain-following curvilinear coordinates, the vertical resolution ranges from 1 to $4.7 \mathrm{~m}$ at the surface and from 3.1 to $1030 \mathrm{~m}$ at the bottom. The model is forced by winds, heat fluxes and fresh water fluxes derived from the COADS ocean surface monthly climatology at 0.5 degree resolution (da Silva et al. 1994). At the 3 lateral boundaries facing the open ocean, a specific scheme (Marchesiello et al. 2001) connects the model solution to cyclic seasonal, time-averaged outputs of the 'Agulhas as primitive equations' (AGAPE) basin scale ocean model (Biastoch \& Krauß 1999).

The summer values of the AGAPE climatology are used for the initial conditions. The domain being relatively small, the solution, starting from rest, quickly adjusts to the initial stratification and the model reaches a statistical equilibrium after a spin-up of

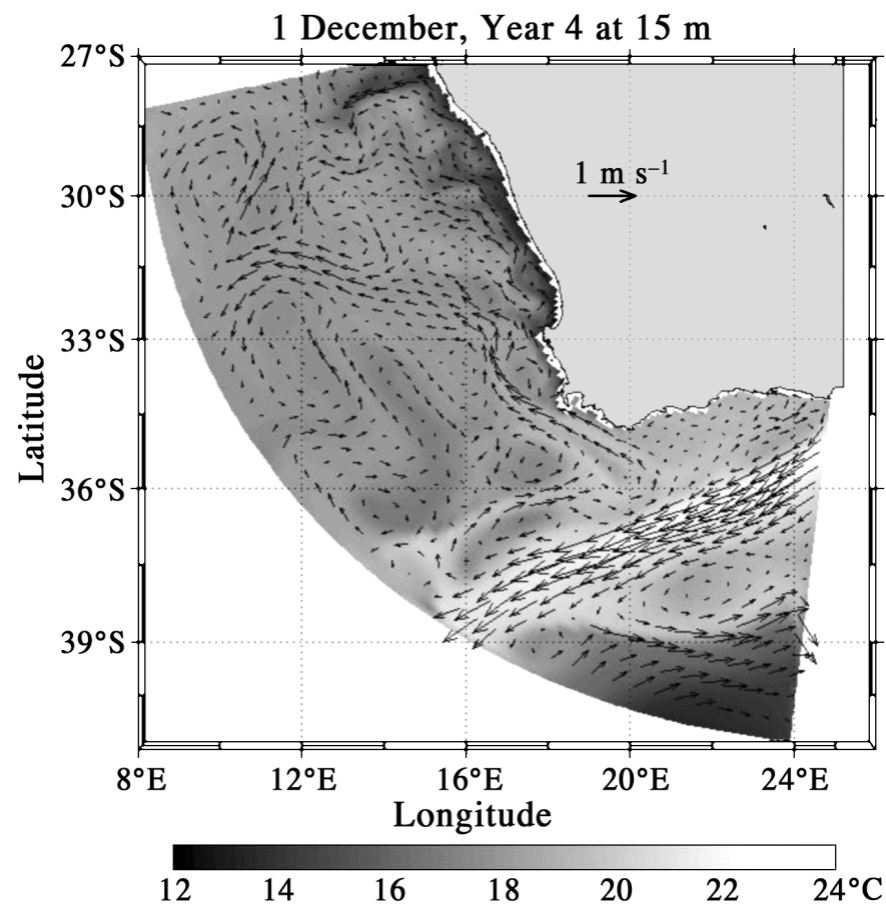

Fig. 3. Example of the Plume model output, showing average sea surface temperature $\left(\mathrm{SST}_{i}{ }^{\circ} \mathrm{C}\right)$ and surface currents $\left(\mathrm{m} \mathrm{s}^{-1}\right)$ for 1 December during Year 4 of the model at a depth of $15 \mathrm{~m}$ about 1 to 2 yr (Penven 2000). Since the dynamics in this area are highly turbulent, one should expect to find slight differences in the model solution from one year to another, even if the forcing is identical each year and the solution is already at equilibrium.

The particle-tracking model. The model was designed to simulate the Lagrangian transport of particles (anchovy eggs that subsequently develop into anchovy larvae, although our model considers a single category of particles) from the Agulhas Bank spawning grounds to the west coast nursery area. The particletracking algorithm, which is based on a Eulerian scheme, was written by the authors. It samples the output of the hydrodynamic model every $48 \mathrm{~h}$ but interpolates the data at 5 time steps during each $48 \mathrm{~h}$ period. This time step was selected after checking the sensitivity of the model to this interval. The algorithm does not include any turbulent diffusion; visualisation of the relative displacement of the particles obtained with passive transport indicated that the currents were very 'diffusive' without explicit diffusion.

Fixed parameters: These included: (1) the release of 10000 particles per run in order to ensure stability in the outputs of the model despite the incorporation of random factors, (2) a random vertical distribution of the particles between the surface and $60 \mathrm{~m}$ based on our limited knowledge of spawning depth, (3) a spawning period of 1 mo repeated 12 times in order to investigate transport success all year round, and (4) a tracking period of $60 \mathrm{~d}$.

Transport success was defined as particles that were passively transported to the nursery area within a time interval of 14 to $60 \mathrm{~d}$ after release. The lower limit corresponds to the minimal swimming ability required to avoid advection upon arrival in the low-current nursery area, whereas the upper limit corresponds to the maximum swimming ability at which the fish may still be considered as a passive particle in an area of strong flow. These limits are based on our perception of swimming capability from measured and estimated stage-specific growth rates (King et al. 1978, Armstrong \& Thomas 1989, Huggett et al. 1998), as well as observed size in the inshore nursery grounds (Hutchings et al. 1998, van der Lingen \& Merkle 1999). The nursery area was divided into 2 regions: the inshore nursery, the 0 to $200 \mathrm{~m}$ shelf region between Cape Columbine and the Orange River, which is considered to be the core of the nursery area; and the offshore nursery, the 200 to $500 \mathrm{~m}$ shelf region between Cape Columbine and the Orange River (Fig. 2).

Variable parameters: Particles were released from 5 different spawning areas ('Area'): (1) the western Agulhas Bank (WAB) between Cape Point and Cape Agulhas from 0 to $500 \mathrm{~m}$ depth, (2) the inshore central Agulhas Bank (CAB in) between Cape Agulhas and 
Fig. 4. Engraulis encrasicolus. Composite distribution map of anchovy eggs $\left(\right.$ no. $\mathrm{m}^{-2}$ ) collected with a CalVET net during annual (November) pelagic spawner biomass surveys over the period 1983 to 1999 (C. van der Lingen pers. comm.)

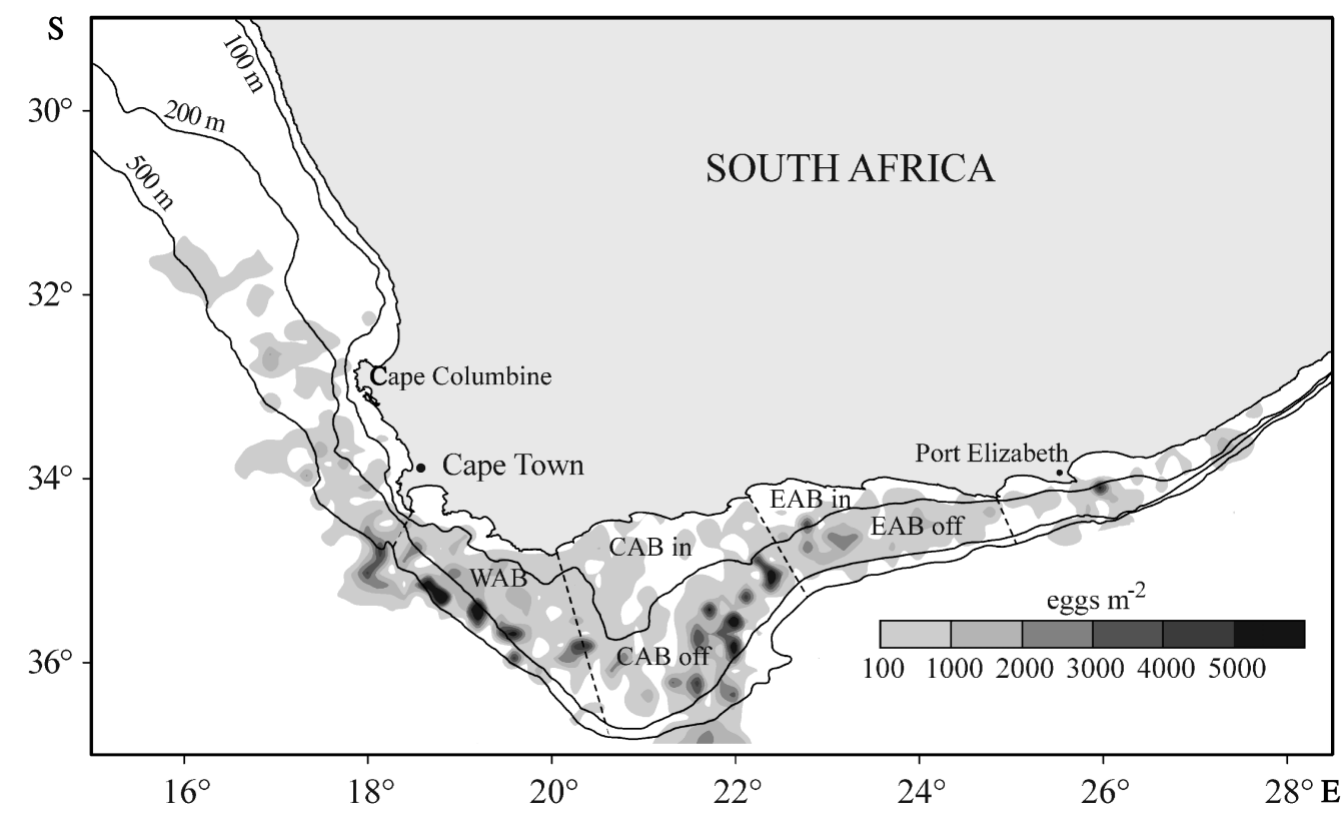

Mossel Bay, from 0 to $100 \mathrm{~m}$ depth, (3) the offshore central Agulhas Bank (CAB off), as above, but from 100 to $500 \mathrm{~m}$ depth, (4) the inshore eastern Agulhas Bank (EAB in) between Mossel Bay and Cape St Francis, from 0 to $100 \mathrm{~m}$ depth, and (5) the offshore eastern Agulhas Bank (EAB off) as above, from 100 to $500 \mathrm{~m}$ depth.

These areas cover the main spawning grounds of anchovy and their boundaries are inspired by current convention in the region. The $100 \mathrm{~m}$ depth contour is used $^{1}$ on the central and eastern Agulhas Bank to split these areas into low spawning-intensity coastal zones and high spawning-intensity offshore zones (Fig. 4).

Other variable parameters included month of particle release or 'spawning event' ('Month', varying from January to December), the successive year of the simulation model ('Year', varying from 4 to 8), particle patchiness ('Patchiness', discrete values of 1, 10 or 100 corresponding to 10000 random releases of 1 particle in the spawning area, 1000 random releases of 10 particles in $1 \mathrm{~km}^{2}$ and 100 random releases of 100 particles in $1 \mathrm{~km}^{2}$, respectively), and frequency of 'spawning event' ('Frequency', discrete values of 1, 3 or 10 corresponding to the release of particles every 1,3 or $10 \mathrm{~d} \mathrm{mo}^{-1}$, respectively). Due to our limited knowledge of the spawning behaviour of anchovy, Patchiness and Frequency were incorporated in the model in order to test the effect of non-randomness in the spatial and temporal distribution of particle release. Three trials of

\footnotetext{
${ }^{1}$ Due to the smoothing of the bathymetry imposed by some constraints in the Plume model, we had to use the $125 \mathrm{~m}$ depth contour in the hydrodynamic model in order to represent the $100 \mathrm{~m}$ depth contour accurately
}

each permutation were run, resulting in 8100 simulated spawning events and a total of over 24 million particles released (Table 1).

Assumptions. A number of implicit and explicit assumptions were made:

- The resolution, forcing, and topography employed in the Plume model produced sufficiently realistic circulation patterns; short-term $(<1 \mathrm{mo})$ wind events did not significantly affect the transport of spawning products from the spawning grounds to the nursery area

- Significant spawning (in terms of reproductive success) only occurs on the Agulhas Bank, from Cape Point to Cape St Francis between the coast and the $500 \mathrm{~m}$ isobath

- The subdivision of the spawning area into 5 subareas (Fig. 2) was adequate to explore the influence of spatial variability on reproductive success

- The vertical distribution of eggs released by fish was assumed to be homogeneous in the upper $60 \mathrm{~m}$, and any departure from this assumption would not significantly affect transport success

- Eggs and larvae are mainly transported in a Lagrangian mode and the effects of ichthyoplankton density, diffusion and active movement are negligible in comparison to this fast mode of transport

- Transport success was achieved when particles reached the nursery area within a time interval of 14 to $60 \mathrm{~d}$ after release

- The release of 10000 particles in the model during each run was sufficient to ensure stability in the outputs of the model (i.e. variability due to random factors in the model was taken into account) 
Table 1. Number of particles released in the individual-based model (IBM) and percentage of particles successfully transported to the 2 nursery regions, for each parameter. WAB: western Agulhas Bank; CAB: central Agulhas Bank: EAB: eastern Agulhas Bank; 'in' and 'off' after abbreviation means 'inshore' and 'offshore', respectively

\begin{tabular}{|c|c|c|c|}
\hline \multirow[t]{2}{*}{ Parameter } & \multirow[t]{2}{*}{$\begin{array}{l}\text { No. of particles } \\
\text { released }\end{array}$} & \multicolumn{2}{|c|}{$\begin{array}{l}\text { \% successfully } \\
\text { transported to: }\end{array}$} \\
\hline & & $\begin{array}{l}\text { inshore } \\
\text { nursery }\end{array}$ & $\begin{array}{l}\text { offshore } \\
\text { nursery }\end{array}$ \\
\hline \multicolumn{4}{|l|}{ Month } \\
\hline January & 2025000 & 1.25 & 14.96 \\
\hline February & 2025000 & 1.09 & 12.40 \\
\hline March & 2025000 & 1.39 & 9.03 \\
\hline April & 2025000 & 1.86 & 5.11 \\
\hline May & 2025000 & 1.57 & 2.71 \\
\hline June & 2025000 & 1.23 & 1.88 \\
\hline July & 2025000 & 1.56 & 2.76 \\
\hline August & 2025000 & 3.15 & 6.95 \\
\hline September & 2025000 & 3.67 & 12.49 \\
\hline October & 2025000 & 2.84 & 15.51 \\
\hline November & 2025000 & 1.75 & 17.79 \\
\hline December & 2025000 & 1.44 & 17.78 \\
\hline \multicolumn{4}{|l|}{ Area } \\
\hline WAB & 2977100 & 10.01 & 33.79 \\
\hline CAB in & 7766485 & 1.16 & 9.92 \\
\hline CAB off & 5447995 & 1.27 & 8.66 \\
\hline EAB in & 2157478 & 0.13 & 3.84 \\
\hline EAB off & 5950942 & 0.03 & 1.49 \\
\hline \multicolumn{4}{|l|}{ Year } \\
\hline 4 & 4860000 & 1.25 & 8.07 \\
\hline 5 & 4860000 & 2.05 & 8.66 \\
\hline 6 & 4860000 & 1.56 & 9.65 \\
\hline 7 & 4860000 & 2.71 & 13.00 \\
\hline 8 & 4860000 & 1.93 & 10.40 \\
\hline \multicolumn{4}{|l|}{ Patchiness } \\
\hline 1 & 8100000 & 1.91 & 9.95 \\
\hline 10 & 8100000 & 1.88 & 9.92 \\
\hline 100 & 8100000 & 1.91 & 10.00 \\
\hline \multicolumn{4}{|l|}{ Frequency } \\
\hline 1 & 8100000 & 1.92 & 10.01 \\
\hline 3 & 8100000 & 1.87 & 9.92 \\
\hline 10 & 8100000 & 1.91 & 9.94 \\
\hline Total & 24300000 & 1.90 & 9.96 \\
\hline
\end{tabular}

Sensitivity analysis and validation. A sensitivity analysis of transport success as the dependent variable was performed on the 5 independent class variables (Table 1) using multifactor analysis of variance that we will abbreviate as ANOVA in the rest of the text. We used the 'visual general linear model' module of StatSoft (2000), although there was no continuous independent variable in our model. We first ran a full crossed model with all possible interactions up to the 3rd degree (3-way interactions). A stepwise procedure was then used to manually select a more parsimonious 'suboptimal' ANOVA. Because the number of data points is high and the design is fully balanced, an optimal ANOVA (including all the significant variables) would be over-parameterised, and some parameter estimates would be biased and/or not unique estimators. As stressed by Lebreton et al. (1992), instead of intending to obtain the ideal model explaining the highest percentage of variance, it is preferable to allow some secondary and hypothetical effects in the residuals and to focus on the main effects in the model. A visual residual analysis was performed to check for normality in the distribution of residuals, and to ensure that there was no trend in the mean and variance of residuals plotted against observed values. Results of the ANOVA were interpreted in the context of observed distributions of anchovy eggs during annual surveys of spawner biomass on the Agulhas Bank, as well as of seasonal spawning patterns from the literature and ongoing monitoring programmes.

The model output was compared to monthly patterns of anchovy egg abundance from 2 historical ichthyoplankton surveys, namely the 'early routine' surveys and the Cape egg and larval programme (CELP) survey, plus 1 monitoring line, the sardine and anchovy recruitment programme (SARP) line. Both surveys were conducted off the SW coast of South Africa between Lamberts Bay and Cape Infanta (Fig. 2). During the 'early routine' surveys from 1965 to 1967 , anchovy eggs were collected using a N100H/70 net $\left(0.78 \mathrm{~m}^{2}\right.$ mouth area, $220 \mu \mathrm{m}$ mesh) towed horizontally just below the surface for 5 min (Crawford 1981). During the CELP survey from 1977 to 1978, anchovy eggs were collected using double oblique hauls of a Bongo sampler $\left(0.25 \mathrm{~m}^{2}\right.$ mouth area, $300 \mu \mathrm{m}$ mesh) to a maximum depth of $100 \mathrm{~m}$ (Shelton 1986). The SARP monitoring line (1995 to 2001) comprised regular sampling along a 40 mile transect crossing the Benguela jet current off the Cape Peninsula (Fig. 2). Monitoring along this transect was initiated in August 1995, with samples collected twice per month on average from stations located at 3-mile intervals $(\sim 4.8 \mathrm{~km})$ along the transect. Ichthyoplankton samples were collected with a mini-Bongo net sampler $\left(0.025 \mathrm{~m}^{2}\right.$ mouth area, $300 \mu \mathrm{m}$ mesh) lowered to $70 \mathrm{~m}$ while the vessel was stationary, and then towed obliquely through the water to the surface at 1 to $2 \mathrm{~m} \mathrm{~s}^{-1}$ (Huggett et al. 1998). As the methods varied in all of these surveys, monthly egg abundance was expressed as a percentage of total annual abundance.

\section{RESULTS}

Success of transport to the 2 nursery regions for all parameters investigated is shown in Table 1. It is expressed as the ratio of successful particles arriving in the nursery area to the number of particles released in a given area. Transport success was relatively high for the offshore nursery region, attaining $10 \%$. In contrast, 
Table 2. Results of a 3-way interaction ANOVA performed on successful transport of particles to the offshore nursery region. The factors retained for the suboptimal ANOVA are given in bold. ${ }^{*} p<0.05,{ }^{* * *} p<0.001$

\begin{tabular}{|c|c|c|c|c|c|c|}
\hline Factor & $\begin{array}{l}\% \text { variance } \\
\text { explained }\end{array}$ & SS & $\mathrm{df}$ & MS & $F$ & $\mathrm{p}$ \\
\hline Year & 2.1 & 21573755 & 4 & 5393439 & 608.3 & $* * *$ \\
\hline Area & 41.2 & 414463492 & 4 & 103615873 & 11686.0 & ${ }^{* * *}$ \\
\hline Month & 23.9 & 240207065 & 11 & 21837006 & 2462.8 & $* * *$ \\
\hline Patchiness & 0.0 & 8709 & 2 & 4354 & 0.5 & \\
\hline Frequency & 0.0 & 11921 & 2 & 5961 & 0.7 & \\
\hline Year $\times$ Area & 0.8 & 8357749 & 16 & 522359 & 58.9 & $* * *$ \\
\hline Year $\times$ Month & 5.9 & 59702055 & 44 & 1356865 & 153.0 & $* * *$ \\
\hline Area $\times$ Month & 17.3 & 174256407 & 44 & 3960373 & 446.7 & $* * *$ \\
\hline Year $\times$ Patchiness & 0.0 & 70796 & 8 & 8849 & 1.0 & \\
\hline Area $\times$ Patchiness & 0.0 & 55763 & 8 & 6970 & 0.8 & \\
\hline Month $\times$ Patchiness & 0.0 & 100934 & 22 & 4588 & 0.5 & \\
\hline Year × Frequency & 0.0 & 74666 & 8 & 9333 & 1.1 & \\
\hline Area $\times$ Frequency & 0.0 & 157182 & 8 & 19648 & 2.2 & $*$ \\
\hline Month $\times$ Frequency & 0.3 & 26887272 & 22 & 122217 & 13.8 & $* * *$ \\
\hline Patchiness $\times$ Frequency & 0.0 & 4219 & 4 & 1055 & 0.1 & \\
\hline Year $\times$ Area $\times$ Month & 7.3 & 73065708 & 176 & 415146 & 46.8 & $* * *$ \\
\hline Year $\times$ Area $\times$ Patchiness & 0.0 & 186787 & 32 & 5837 & 0.7 & \\
\hline Year $\times$ Month $\times$ Patchiness & 0.0 & 448310 & 88 & 5094 & 0.6 & \\
\hline Area $\times$ Month $\times$ Patchiness & 0.1 & 652382 & 88 & 7413 & 0.8 & \\
\hline Year $\times$ Area $\times$ Frequency & 0.0 & 272020 & 32 & 8501 & 1.0 & \\
\hline Year $\times$ Month $\times$ Frequency & 0.3 & 3163567 & 88 & 35950 & 4.1 & $* * *$ \\
\hline Area $\times$ Month $\times$ Frequency & 0.5 & 5523506 & 88 & 62767 & 7.1 & $* * *$ \\
\hline Year $\times$ Patchiness $\times$ Frequency & 0.0 & 997800 & 16 & 6238 & 0.7 & \\
\hline Area $\times$ Patchiness $\times$ Month & 0.0 & 186956 & 16 & 11685 & 1.3 & \\
\hline Month $\times$ Patchiness $\times$ Frequency & 0.0 & 388085 & 44 & 8820 & 1.0 & \\
\hline Model & 94.0 & 1005720606 & 875 & & & \\
\hline Error & 6.0 & 64052903 & 7224 & 8867 & & \\
\hline
\end{tabular}

there was a low overall success rate $(2 \%)$ of particles passively transported to the inshore nursery region and this success was almost exclusively due to particles released in the $\mathrm{WAB}$, where transport success was $10 \%$ compared to $<1.5 \%$ in any of the other areas. Because so few particles released in the latter areas reached the inshore nursery, in the rest of the paper we will concentrate on transport success to the offshore

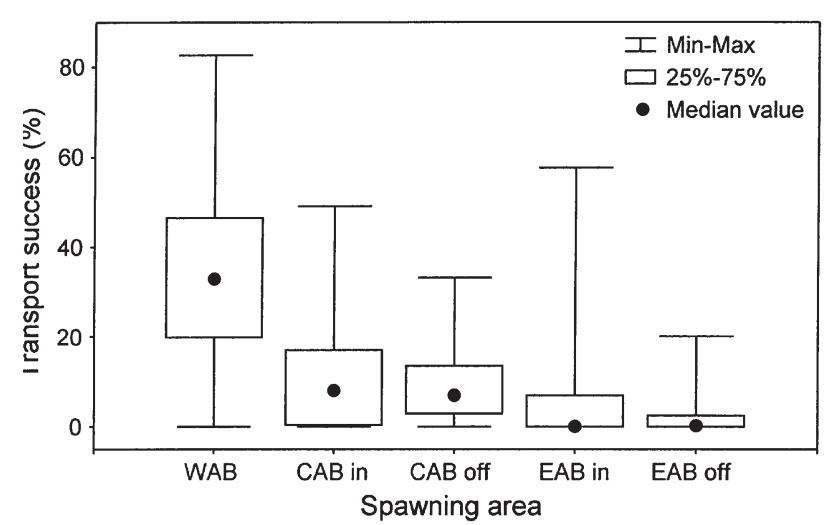

Fig. 5. Engraulis encrasicolus. Transport success (\%) to the offshore nursery area in relation to spawning area (Area as variable) nursery region and only briefly mention transport success to the inshore nursery for the WAB area.

The results of the full crossed ANOVA for the simulation on the offshore nursery region are shown in Table 2. Area, Month and Year were significant, with Area explaining most of the variance (41\%). Month and Year explained 24 and $2 \%$ of the variance, respectively. Neither Patchiness nor Frequency had a significant

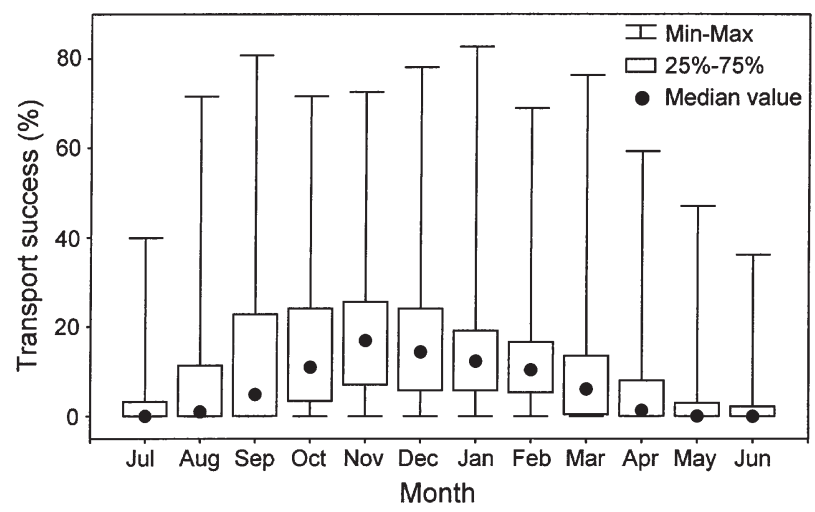

Fig. 6. Engraulis encrasicolus. Transport success (\%) to the offshore nursery area in relation to month of spawning (Month as variable) 


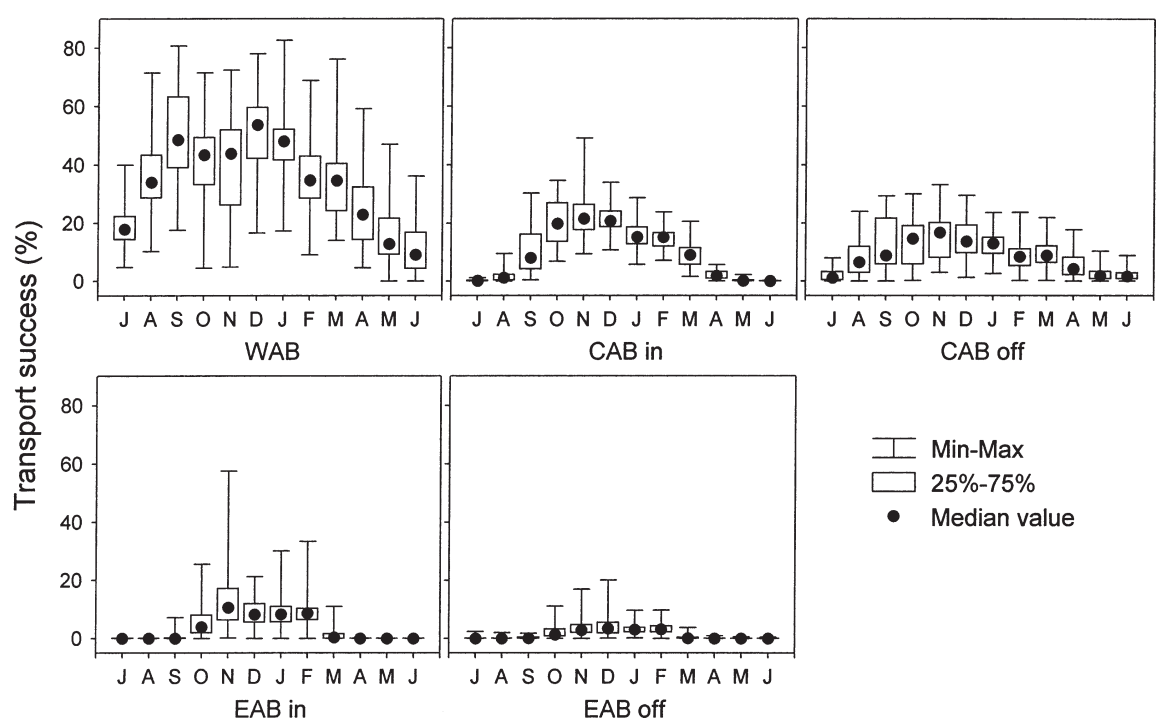

Fig. 7. Engraulis encrasicolus. Transport success (\%) to the offshore nursery area in relation to spawning area (Area as variable) and month of spawning (Month as variable)

effect on transport success, and explained less than $0.001 \%$ of the variance. The most significant interactions were between Area and Month (17.3\% of the variance), Year, Area and Month (7.3\%) and Year and Month (5.9\%). The variables incorporated in the ANOVA explained $94 \%$ of the variance, with $6 \%$ of the variance attributable to error (randomness in the distribution of the particles). The suboptimal ANOVA (retained factors shown in bold in Table 2) explained 92\% of the total variance and the contribution of each factor was very similar (not shown). The residual analysis performed on both models (full cross and suboptimal) indicated normality in the distribution of residuals and no trend in the mean and variance of residuals when plotted against observed values (results not shown).

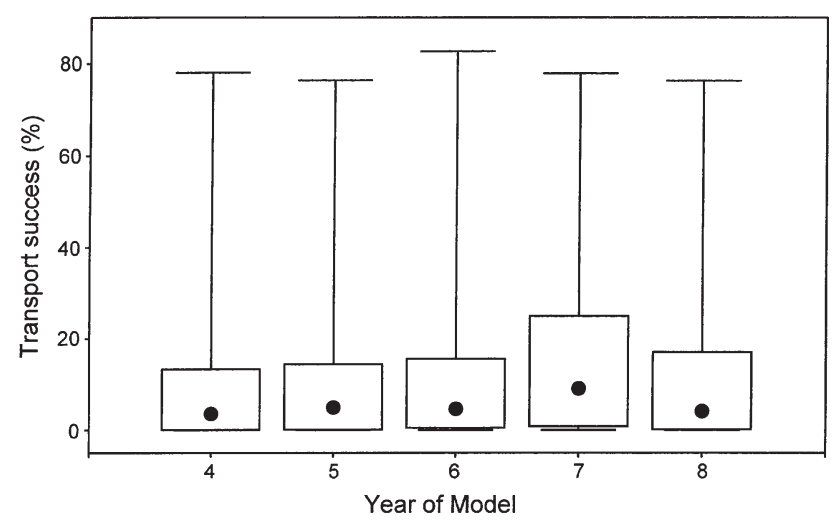

Fig. 8. Engraulis encrasicolus. Transport success (\%) to the offshore nursery area in relation to the year of the Plume model (Year as variable)
Transport success of particles to the nursery area displayed considerable variability in relation to both spatial and temporal release patterns. The WAB was the best area for spawning in terms of successful transport of particles to both the inshore and offshore nursery regions (Fig. 5), followed by the inshore $\mathrm{CAB}$, the offshore $\mathrm{CAB}$ and lastly the 2 EAB areas. Temporally, overall transport success to the offshore nursery region was highest for particles released between September and March, gradually declining to lowest levels in the winter months of June and July (Fig. 6). In contrast, transport success from the WAB to the inshore nursery showed a different pattern, with a narrower peak in August-September (results not shown).

The ANOVA revealed a substantial interaction between the timing and location of particle release on the success of transport to the offshore nursery region (Fig. 7), with different patterns of variation for the WAB and the offshore $\mathrm{CAB}$ compared to other areas. The WAB and offshore CAB showed a protracted successful season of 9 mo, with relatively low values only from May to July, while in the other areas successful transport was observed during 5 (EAB areas) to 7 mo (CAB in). Nonetheless, a feature common to all areas was relatively high transport success from November to February.

There was some 'interannual' variability in transport success (Fig. 8), with lowest virtual transport in Year 4 of the model $(8 \%)$ and highest in Year $7(13 \%$, Table 2). There was a significant but moderate interaction between Year and Month, and despite some slight variation from year to year, the general seasonal pattern described in Fig. 6 was observed during all years.

\section{DISCUSSION}

\section{Spatial and temporal spawning patterns}

The large contribution of month and area of particle release, as well as the interaction between these variables, to successful transport in the model supports our first hypothesis. From a strictly spatial point of view, the highest transport success associated with particle release on the WAB in the simulation model agrees well with the observed occurrence of most anchovy eggs on the WAB during the acoustic pelagic biomass surveys conducted during November each year (Fig. 4), and supports the view that the WAB is the most 
important spawning area for recruitment to the west coast because it is the most favourable region for transport of eggs and larvae to the west coast nursery area (Peterson et al. 1992, Cochrane \& Hutchings 1995, Mullon et al. 2002). Whereas most anchovy eggs have historically been found on the WAB, eggs are also often concentrated on the offshore $\mathrm{CAB}$ near the shelf edge, the third most successful area for spawning in terms of the simulation model. It may thus seem surprising that the model indicated that the inshore $\mathrm{CAB}$ yielded slightly more successful transport than the offshore $C A B$, but of course processes other than transport are involved in the selection of spawning habitat, and they are not taken into account in this model. The band of anchovy eggs on the offshore $\mathrm{CAB}$ (Fig. 4) is sandwiched between a quasi-permanent ridge of subsurface cool water which extends south-westwards from the EAB to the CAB (Swart \& Largier 1987, Boyd \& Shillington 1994) and the fast-flowing Agulhas Current. As 16 to $19^{\circ} \mathrm{C}$ water is optimal for anchovy egg development (Richardson et al. 1998), the shallow thermocline and cool $\left(<14^{\circ} \mathrm{C}\right)$ water associated with the ridge may preclude extensive spawning in this region (Hutchings 1994), which incorporates much of the inshore $\mathrm{CAB}$.

The least successful areas, in terms of transport to the west coast nursery region, were the $2 \mathrm{EAB}$ areas, where eggs were found in low to moderate densities during the November surveys (Fig. 4). The discrepancy between the very low transport success from the offshore $\mathrm{EAB}$ and the moderate spawning activity that occurs in this area is largely due to our criteria of max-

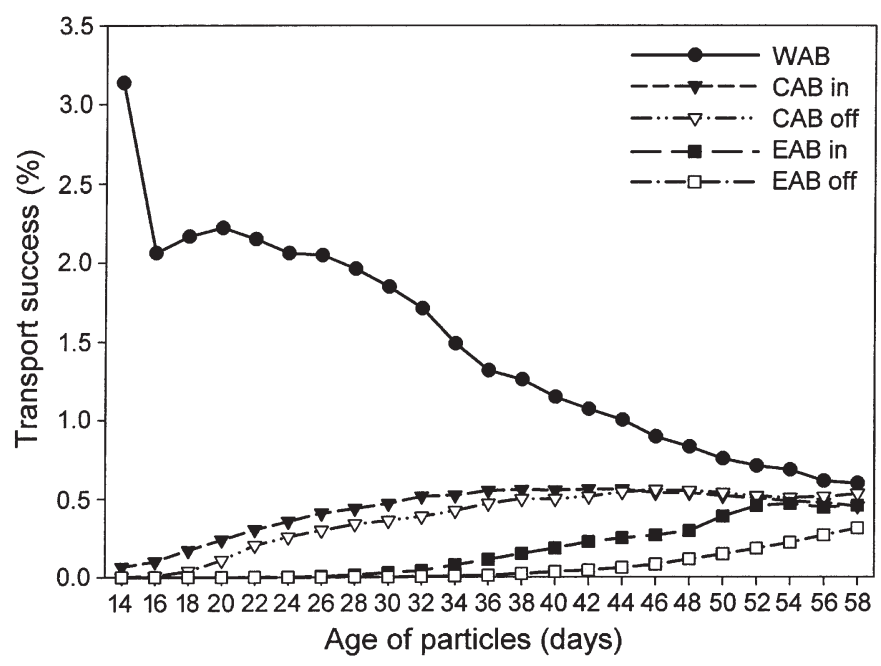

Fig. 9. Engraulis encrasicolus. Non-cumulative transport success $(\%)$ to the offshore nursery region according to the age of the particles released from different spawning areas (see Fig. 2 for their location and full names; 'in' and 'off' after abbreviation means 'inshore' and 'offshore', respectively) imum age at the end of the transport phase $(60 \mathrm{~d})$. Particles released from the offshore EAB began arriving in the offshore nursery area $28 \mathrm{~d}$ after their release, and were still transported to the distant nursery ground at $60 \mathrm{~d}$, and certainly thereafter (Fig. 9). Indeed, despite their low catchability, significant numbers of large and presumably older larvae are caught along the SARP line long after the decline in egg abundance (Authors' unpubl. data). At this advanced stage of development, however, the swimming capabilities of the larvae certainly play a major role in the real world. Whether pre-recruits older than 2 mo remain on the spawning grounds or migrate to the nursery area is still unknown.

From a strictly temporal point of view, the model indicates that September to March is the best time of year for anchovy to spawn to ensure transport of eggs and larvae to the nursery grounds, while May to July is the worst time of year. Anchovy spawning may extend from August to April, but most spawning occurs between October and January/February (Crawford 1981, Shelton \& Hutchings 1990, Fowler 1998, Huggett et al. 1998). Armstrong \& Thomas (1989) observed that this period represents a window of time in which the oceanographic conditions on the Agulhas Bank are most suitable for successful spawning by anchovy. Spawning also coincides with a period of surface water drift from the Agulhas Bank around Cape Point and northwards, facilitating transport of eggs and larvae to the west coast. Numerous surveys during summer have revealed a tongue of eggs extending from the WAB up the west coast, indicating the effects of the frontal jet-current on transport (Shelton \& Hutchings

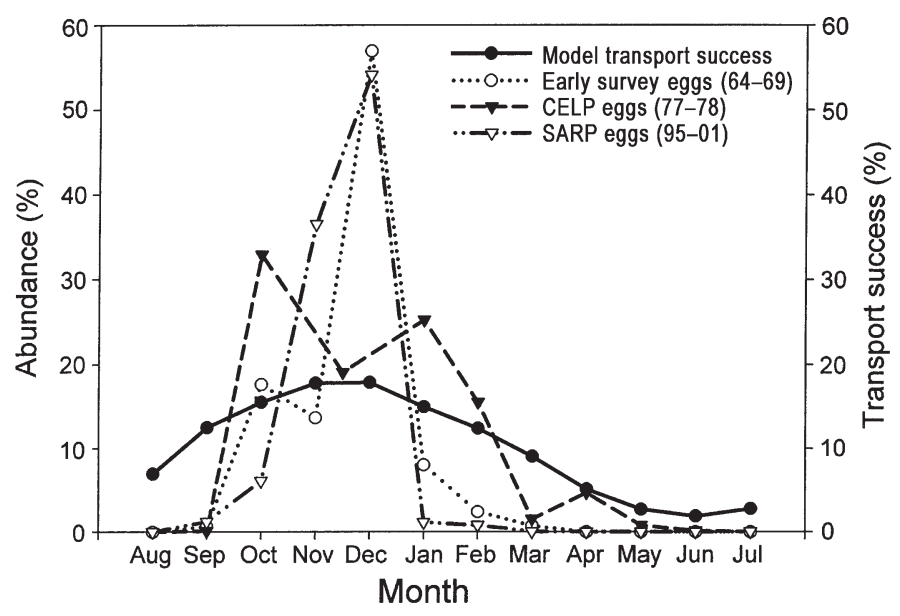

Fig. 10. Engraulis encrasicolus. Relative monthly abundance $(\%)$ of anchovy eggs collected during various surveys off the southwest coast, as well as modelled transport success (\%) to the offshore nursery area for particles released during different months on the Agulhas Bank. CELP: Cape egg and larval programme; SARP: sardine and anchovy recruitment programme 


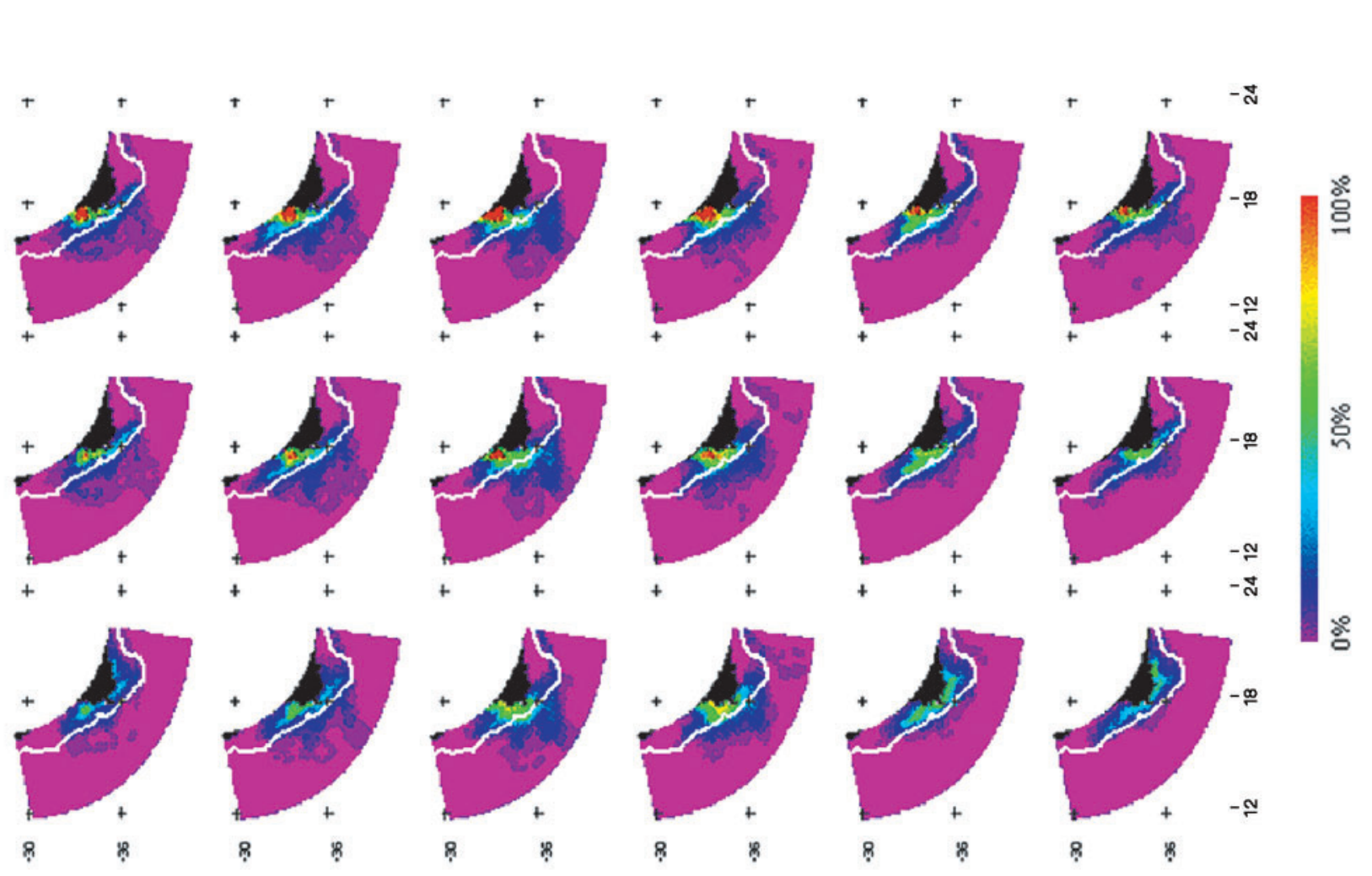

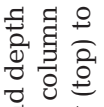

듀 룰

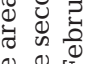

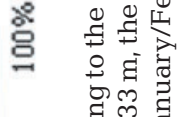

윰

엉 영

ชิ

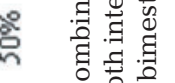

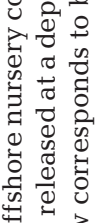

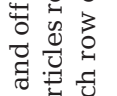

वृ: 규

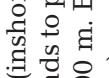

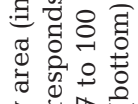

으
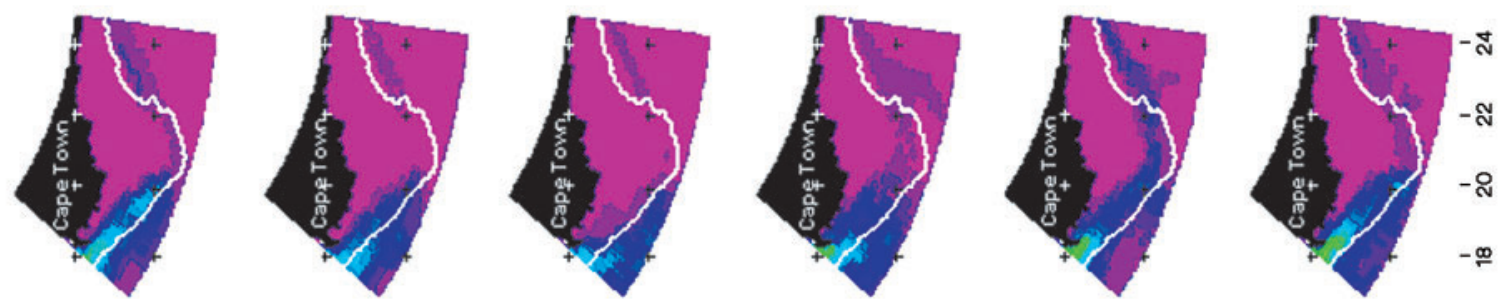

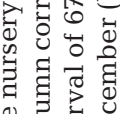
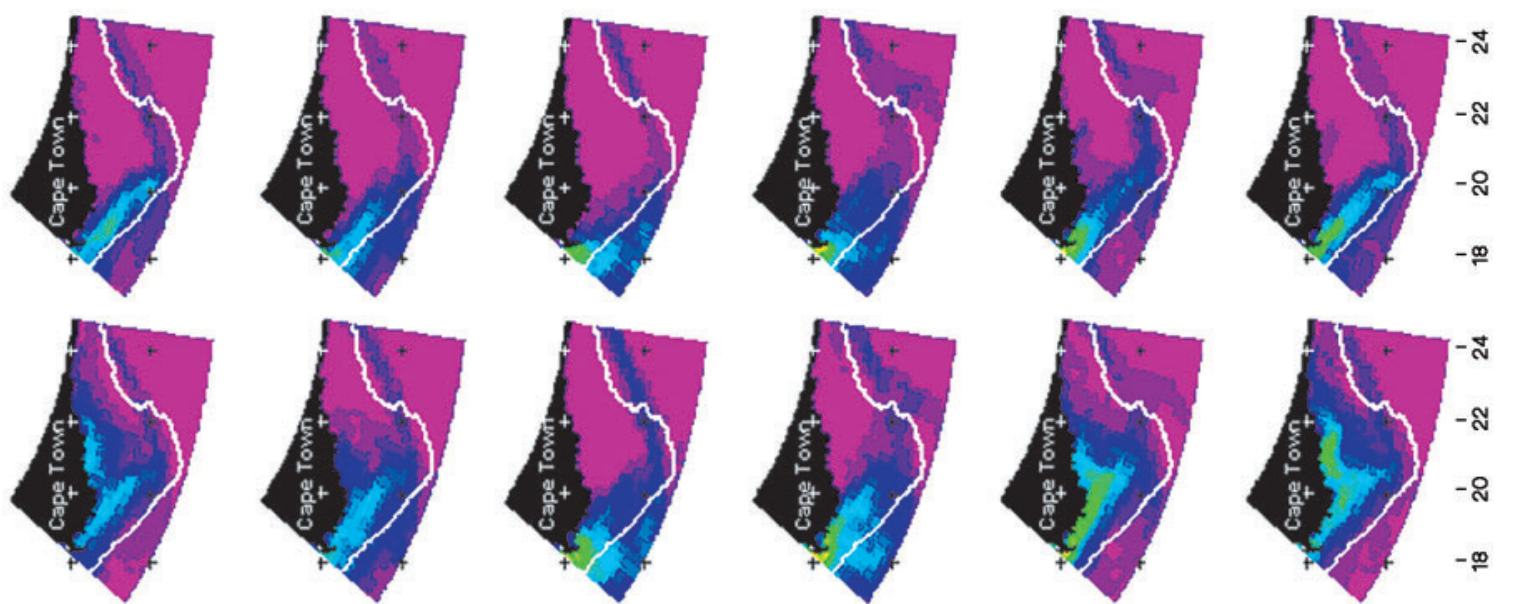

ষ

क

ฆ ळ

市 के

ชิ

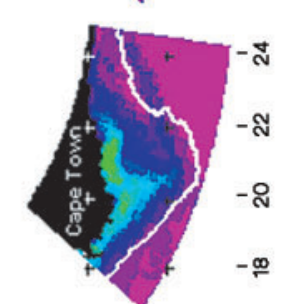

के

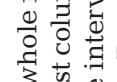

o.

도원

ัํํ

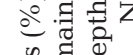

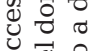

की

눙

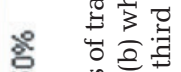

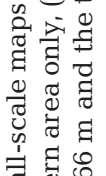

$\therefore$ 韋

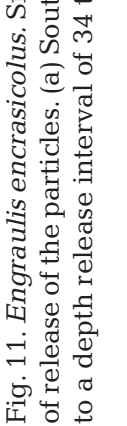


1990, Roel et al. 1994). The seasonality of egg abundance constructed from data collected during early surveys, the CELP survey and along the SARP monitoring line (Fig. 10) confirms that the main spawning activity occurs from September to March/April, although the spawning peaks are sharper in the SARP and 'early routine' survey data than in the transport success simulation for particles reaching the offshore nursery area.

The spatio-temporal effect, as illustrated by the substantial interaction between Area and Month, is more difficult to interpret because most of the acoustic survey data are obtained in November, and we have little information on spatial spawning patterns during the rest of the year. For instance, in our model, transport from the WAB to both inshore and offshore nursery regions peaks in September, but there is no evidence of more spawning activity in September in this region than later during the spawning season. Monthly egg and larval surveys during 2 consecutive spring/ summer upwelling seasons indicated greatest egg abundance during October and November on the WAB, with relatively low egg abundance during September (Painting et al. 1998).

The moderate interannual variability in transport success can only be attributed to varying mesoscale processes, which result from intrinsic instabilities of the ocean dynamics incorporated into the hydrodynamic model, despite the smoothed and repeated pattern of seasonal forcing conditions (Penven 2000, Penven et al. 2001a).

Neither spawning frequency nor spawning patchiness contributed significantly to transport success (2nd and 3rd hypotheses therefore rejected). Therefore, in the following steps of our model, we will not have to incorporate these factors and will thus limit the risk of over-parameterisation of the model.

\section{Passive transport to the nursery region}

The overall success rate of transport to the core coastal area of recruitment (inshore nursery) is low in the model $(2 \%)$. Although the high individual lifetime fecundity of anchovy (about 100000 eggs per female; Armstrong et al. 1988, Melo 1994, Motos 1996) implies that a survival rate as low as $0.002 \%$ is theoretically sufficient to maintain the equilibrium of the population, a number of other sources of natural mortality besides offshore advection have been identified, such as predation, starvation, and lethal temperature (Hutchings 1992, Hutchings \& Boyd 1992). Moreover, short-lived pelagic species like anchovy have to deal with extreme environmental changes, and some authors argue that their high fecundity is part of an opportunistic strategy to colonise or re-colonise remote areas (reviewed in Bakun 1996). All these reasons suggest that additional processes are required for larvae to reach the inshore nursery region (fourth hypothesis therefore rejected). Indeed, a positive offshore-inshore gradient in the length of larvae has been observed, with larvae $<20 \mathrm{~mm}$ located offshore and those $>35 \mathrm{~mm}$ located inshore (van der Lingen \& Merkle 1999), suggesting a slow offshore-inshore migration, either passive or active.

The simplest solution for ensuring the successful arrival in the nursery area of larvae transported offshore is that those larvae swim towards the coast as soon as they are able to. Recent studies on the return migration of coral reef fish species advected far away from reefs indicate that in Acanthurid species, such young post-larvae have astonishing swimming capabilities even when starving in oligotrophic areas. They are able to swim continuously for several days at average speeds up to $0.13 \mathrm{~m} \mathrm{~s}^{-1}$, covering the equivalent of $194 \mathrm{~km}$ (Stobutzki 1998).

An alternative, but not mutually exclusive, hypothesis is that the larvae are carried or advected inshore by currents. This could occur through 2 different processes. Larvae could either migrate vertically to the depth of the upwelling Ekman inshore compensatory flow (below $50 \mathrm{~m}$ ), although there is no data to support this theory, or else they could remain in the upper layer and benefit from transport during relaxation of the upwelling favourable winds (Armstrong \& Thomas 1989). At present our hydrodynamic model is forced by a monthly climatology, and does not allow us to explore this scenario of high frequency wind relaxation.

\section{Assumptions in the model}

Certain implicit or explicit assumptions presented earlier can now be addressed; others are still under investigation or are not presently testable. Validation of the Plume model was largely achieved. The simulated surface currents, averaged from Year 2 to Year 10, compare remarkably well visually with the existing current measurements in the southern Benguela (Penven 2000). The variance of sea surface height, the level of surface kinetic energy and the mean sea surface temperature also compare well with satellite measurements (Penven 2000, Penven et al. 2001a). The only major discrepancy was too low temperatures on the west coast, which was attributed to the coarse spatial and temporal resolution of the COADS wind product used to force the model. The model is also able to reproduce typical processes associated with the Agulhas Current such as the generation of cyclonic eddies from the southern tip of the 
Agulhas Bank (Penven et al. 2001b) and the generation of shear edge eddies (Lutjeharms et al. in press). These results give us confidence in the reliability of the model outputs to reproduce a typical oceanic state for the southern Benguela.

The location of the major spawning grounds (restricted to the Agulhas Bank) is supported by numerous surveys (Hampton 1987, 1992, Barange et al. 1999). The subdivision of the spawning grounds into the 5 subareas shown in Fig. 2, inspired by current practice in the region, could be debated, however. We tested the suitability of this subdivision by displaying probability maps of transport success at a much smaller scale. We repeated the experiments with spawning areas as small as 3 cells of the Plume models ( $13 \times 30 \mathrm{~km}$ on average) and used a colour chart to map the results of successful transport to the whole nursery area (Fig. 11a). From this figure, it appears that the spatial variability of transport success within our pre-defined areas is not very substantial, except for the WAB throughout the year. High success rates were observed beyond the continental shelf, especially during winter outside the WAB, an area where, according to many acoustic surveys, anchovy are seldom observed (Hampton 1992, Barange et al. 1999). However, a number of anchovy eggs have been observed in this area (Fig. 4), clearly transported there from adjacent shelf regions.

Further north along the west coast, the success rate is even higher (Fig. 11b), despite the fact that spawning is not frequently observed in this region (Hampton 1992, Barange et al. 1999). We interpret this as an adaptive strategy of this species originating from the temperate northern hemisphere. It is now accepted (Whitehead 1990) that the anchovy species formerly named Engraulis capensis (Gilchrist 1913) and considered to be endemic, is in fact the same species as the European anchovy E. encrasicolus (Linnaeus 1758). This is thought to result from a recolonisation of the area by E. encrasicolus within the last few 10s or 1000s of years after a previous Southern African population had become extinct (Grant \& Bowen 1998). In fish, thermal tolerance of eggs is lower than that of larvae, which in turn is much lower than that of adult fish (Hempel 1979, Bunn et al. 2000). E. encrasicolus managed to colonise the cold upwelling area off the west coast (annual average temperature ranging from 14 to $16^{\circ} \mathrm{C}$ on the continental shelf [Shillington \& Nykjaer 2002], but frequently dropping below $12^{\circ} \mathrm{C}$ ), despite relatively high lower thermal tolerance limits of $\sim 12$ and $14^{\circ} \mathrm{C}$ for eggs and larvae, respectively (King et al. 1978). This was achieved by spawning in the warm water of the Agulhas Bank, which firstly allows early development within the thermal constraints of this species, and secondly provides transport to the cold-water nursery ground of more thermally tolerant stages.
There are only 2 local studies depicting the vertical distribution of anchovy eggs (Shelton \& Hutchings 1982, 1990); these indicate that eggs are mainly distributed between the surface and $60 \mathrm{~m}$. A random distribution of particles was selected above any mathematical function because the location of the maximum egg density varied between near-surface and approximately $40 \mathrm{~m}$, and was even bimodal on 1 occasion. However, there is a need for more discrete vertical sampling in this regard. The maps showing differences in transport success according to depth indicate that the upper layer $(0$ to $33 \mathrm{~m}$ ) on the Agulhas Bank is more favourable than the intermediate layer (34 to $66 \mathrm{~m})$, while the deeper layer $(67$ to $90 \mathrm{~m}$ ) is generally unfavourable except for the western limit of the WAB and in the region farther offshore where the sea floor is deeper than $500 \mathrm{~m}$ (Fig. 11a). In contrast, transport success on the west coast is most successful for particles released in the deeper layer (Fig. 11b).

In addition to the Lagrangian transport of particles that we considered in this model, other processes can explain the variability in the distribution of ichthyoplankton, such as the density differential between the particles and the seawater, diffusion processes and directional swimming. Anchovy egg density is very close to seawater density, varying from 1.021 to $1.027 \mathrm{~g}$ $\mathrm{cm}^{-3}$ (C. van der Lingen pers. comm.). An ongoing study on the effect of particle density on transport success indicates that this factor is highly significant in the IBM model, even if egg density alone is taken into account during the first $6 \mathrm{~d}$ of the simulation (contribution to the total variance is $17.5 \%$, C. Parada \& C. van der Lingen pers. comm.). Diffusion is not incorporated in our model at this stage. Diffusion would be expected to increase the dispersion of the particles and possibly increase the variance in our results (Cowen et al. 2000). Nonetheless, it should not dramatically change the relative transport success according to the other factors incorporated in the model. Directional swimming and diel vertical migration are by far the most likely factors to change our results dramatically, but we did not incorporate them in the model, firstly because we wished to concentrate only on passive transport during this first step of the simulation, and secondly because we do not yet know the swimming capability and orientation of the larvae.

The number of particles released in the model (10 000) during each run was sufficient to ensure stability in the outputs of the IBM model, since only 6 and $8 \%$ of the variance was not explained by the 3-way interaction ANOVA (Table 2) and the suboptimal ANOVA (not shown), respectively. This result was stable for all trials, which was not the case when only 5000 particles were used during preliminary runs of the model. 
By far the most debatable assumption in our model is that transport success is achieved when larvae reach the nursery area within a time interval of 14 to $60 \mathrm{~d}$ after release. This assumption is based on the average developmental stage observed on the nursery grounds and on estimated growth rates that remain uncertain due to the paucity of daily-ageing studies in the region. The upper limit of $60 \mathrm{~d}$ corresponds to the mean estimated time to reach metamorphosis, when larvae are 30 to $35 \mathrm{~mm}$ long (Armstrong \& Thomas 1989). Since larval swimming capabilities are already well developed before reaching this stage, this value is rather conservative. The model suggests that many larvae remain on the Agulhas Bank when older than $2 \mathrm{mo}$, and whether or not these larvae die, survive and remain on the spawning grounds, or move actively or passively to the nursery area, is largely unknown. It has been speculated that eggs spawned on the central and eastern Bank may recruit locally (Roel et al. 1994), but recruits have seldom been observed east of Cape Point during winter, including 2 surveys extending to Port Elizabeth (Barange et al. 1999). A small population of anchovy is known to exist on the east coast ( $\sim 4 \%$ of the total biomass east of Cape Point measured during a survey in August 1986; Armstrong et al. 1991). However, widespread distribution of anchovy eggs (Anders 1975) and larvae (Beckley \& Hewitson 1994) on the east coast between Port Elizabeth and Durban during several surveys suggests local recruitment to this eastern population.

\section{Future research directions}

The results obtained to date provide an incentive to conduct new modelling and laboratory experiments, as well as to collect field data with specific objectives in mind. Future modelling and research objectives should include: (1) IBM modelling experiments to test the effect of other factors (temperature, egg density, feeding, predation, etc.) on the survival of eggs and larvae according to different spawning strategies (in progress), (2) hydrodynamic modelling experiments to test inshore-offshore transport in relation to upwelling relaxation (in progress), (3) investigations of spawner distribution during the early and late phases of the spawning season, (4) surveys to locate pre-recruits older than 2 mo remaining on the Agulhas Bank after the spawning season, (5) multi-layer sampling of larvae to determine their depth distribution at different times of the day, and (6) laboratory experiments to investigate diel vertical migration and swimming capability of postlarvae.

\section{CONCLUSIONS}

The coupling of a 3D hydrodynamic model to a particle-tracking model has proved to be a powerful tool to investigate factors contributing to the transport success of anchovy eggs and larvae in a highly dynamic environment. In order to avoid some of the pitfalls in IBM modelling identified by Grimm (1999), we clearly identified our hypotheses and assumptions, tested some of the assumptions as far as possible, and made use of conventional statistical analyses routinely used for laboratory and field experiments. This approach improves the hypothesis validation process of modelling studies.

The model-derived temporal and spatial patterns of transport success match our knowledge of the spawning habits of anchovy to a large degree. This suggests that the passive transport of early stages plays a major role in shaping the reproductive strategy of this species. In addition to passive transport by currents resulting from a monthly climatology of forcing factors, it is likely that a passive or active offshore-inshore process occurs once the larvae reach the west coast area.

Discrepancies between the model output and observed spatio-temporal spawning patterns may be attributable either to additional (untested) constraints during the life cycle, such as food availability, predator avoidance and optimal temperature, or to an inaccurate representation of the hydrodynamic processes by the 3D model, or finally to incomplete knowledge of the real spatio-temporal distribution of spawning. This last point can be investigated by dedicated surveys concentrating on limited space and time strata, which would provide the beginning of a feedback loop between modelling output and field data.

The modelling tools used in this study have been designed with transportability to other areas in mind, where similar requirements for investigation may appear. Understanding the key processes responsible for recruitment success in relation to the spawning strategy of the species is the first step towards predicting fish-stock abundance fluctuations. In turn, predicting abundance is a major issue for scientists who wish to consider their own role in the decision-making process, as advocated by Clark et al. (2001).

Acknowledgements. This work is a contribution to the joint South African-French program IDYLE, which involves the IRD (Institut de Recherche pour le Développement), Marine and Coastal Management, and the University of Cape Town, as well as the IRD research unit GEODES. We especially thank P. Cury, C. Roy and C. Parada for their help in improving the manuscript. We also thank C. van der Lingen for stimulating discussions, and C. Boucher and L. Drapeau for assistance with some of the figures. 


\section{LITERATURE CITED}

Anders AS (1975) Pilchard and anchovy spawning along the Cape east coast. S Afr Shipp News Fish Ind Rev 30: 53-57

Anderson JT (1988) A review of size dependent survival during pre-recruit stages of fishes in relation to recruitment. J Northwest Atl Fish Soc 8:55-86

Armstrong MJ, Thomas RM (1989) Clupeoids. In: Payne AIL, Crawford RJM (eds) Oceans of life off southern Africa. Vlaeberg Publishers, Cape Town, p 105-129

Armstrong M, Shelton P, Hampton I, Jolly G, Melo Y (1988) Egg production estimates of anchovy biomass in the southern Benguela system. Calif Coop Ocean Fish Invest Rep 29:137-156

Armstrong MJ, Chapman P, Dudley SFJ, Hampton I, Malan PE (1991) Occurrence and population structure of pilchard Sardinops ocellatus, round herring Etrumeus whiteheadi and anchovy Engraulis capensis off the east coast of Southern Africa. S Afr J Mar Sci 11:227-249

Bakun A (1996) Patterns in the ocean: ocean processes and marine population dynamics. University of California Sea Grant Program, San Diego, California, USA, in cooperation with Centro de Investigaciones Biológicas del Noroeste, La Paz, Mexico. California Sea Grant College, University of California, La Jolla

Barange M, Hampton I, Roel BA (1999) Trends in the abundance and distribution of anchovy and sardine on the South African continental shelf in the 1990s, deduced from acoustic surveys. S Afr J Mar Sci 21:367-391

Baumgartner TR, Soutar A, Ferreira-Bartrina V (1992) Reconstruction of the history of Pacific sardine and northern anchovy populations over the past two millennia from sediments of the Santa Barbara Basin, California. Calif Coop Ocean Fish Invest Rep 33:24-40

Beckley LE, Hewitson JD (1994) Distribution and abundance of clupeoid larvae along the east coast of South Africa in 1990/91. S Afr J Mar Sci 14:205-212

Biastoch A, Krauß W (1999) The role of mesoscale eddies in the source regions of the Agulhas Current. J Phys Oceanogr 29:2303-2317

Boyd AJ, Shillington FA (1994) Physical forcing and circulation patterns on the Agulhas Bank. S Afr J Sci 90:114-122

Boyd AJ, Taunton-Clark J, Oberholster GPJ (1992) Spatial features of the near-surface and midwater circulation patterns of western and southern South Africa and their role in the life histories of various commercially fished species. In: Payne AIL, Brink KH, Mann KH, Hilborn R (eds) Benguela trophic functioning. S Afr J Mar Sci 12:189-206

Boyd AJ, Shannon LJ, Schülein FH, Taunton-Clark J (1998) Food, transport and anchovy recruitment in the southern Benguela upwelling system. In: Durand $\mathrm{MH}$, Cury $\mathrm{P}$, Mendelssohn R, Roy C, Bakun A, Pauly D (eds) Global versus local changes in upwelling systems. ORSTOM Editions, Paris, p 195-209

Bunn NA, Fox CJ, Webb T (2000) A literature review of studies on fish egg mortality: implications for the estimation of spawning stock biomass by the annual egg production method. Science Series, Technical Report, CEFAS, Lowestoft 111:1-37

Clark JS, Carpenter SR, Barber M, Collins S and 13 others (2001) Ecological forecasts: an emerging imperative. Science 293:657-660

Cochrane KL, Hutchings L (1995) A structured approach to using biological and environmental parameters to forecast anchovy recruitment. Fish Oceanogr 4:102-127

Cole J, McGlade J (1998) Clupeoid population variability, the environment and satellite imagery in coastal upwelling systems. Rev Fish Biol Fish 8:445-471

Cowen RK, Lwiza KMM, Sponaugle S, Paris C, Olson D (2000) Connectivity of marine populations: open or closed? Science 287:857-859

Crawford RJM (1981) Distribution, availability and movements of anchovy (Engraulis capensis) off South Africa, 1964-1976. Fish Bull (S Afr) 14:51-94

Crawford RJM, Shannon LV, Pollock DE (1987) The Benguela ecosystem. Part IV. The major fish and invertebrate resources. Oceanogr Mar Biol Annu Rev 25:353-505

Cury P, Roy C (1989) Optimal environmental window and pelagic fish recruitment success in upwelling areas. Can J Fish Aquat Sci 56:670-680

da Silva AM, Young CC, Levitus S (1994) Atlas of surface marine data 1994, Vol 1. Algorithms and procedures. NOAA Atlas NESDIS 6. US Department of Commerce, Washington, DC

DeAngelis DL, Gross LJ (eds) 1992 Individual-based models and approaches in ecology: populations, communities and ecosystems. Chapman \& Hall, New York

Fowler JL (1998) Egg and larval ecology of anchovy (Engraulis capensis) and sardine (Sardinops sagax) in the southern Benguela ecosystem. MSc thesis, University of Cape Town

Grant WS, Bowen BW (1998) Shallow population histories in deep evolutionary lineages of marine fishes: insights from sardines and anchovies and lessons for conservation. J Hered 89:415-426

Grimm V (1999) Ten years of individual-based modelling in ecology: what have we learned and what could we learn in the future? Ecol Model 115:129-148

Haidvogel DB, Arango H, Hestrom K, Beckmann A, Malanotte-Rizzoli P, Shchepetkin AF (2000) Model evaluation experiments in the North Atlantic basin: simulations in nonlinear terrain-following coordinates. Dyn Atmos Oceans 32:239-381

Hampton I (1987) Acoustic study on the abundance and distribution of anchovy spawners and recruits in South African waters. In: Payne AIL, Gulland AJ, Brink KH (eds) The Benguela and comparable ecosystems. S Afr J Mar Sci 5:901-917

Hampton I (1992) The role of acoustic surveys in the assessment of pelagic fish resources on the South African continental shelf. In: Payne AIL, Brink KH, Mann KH, Hilborn $\mathrm{R}$ (eds) Benguela trophic functioning. S Afr J Mar Sci 12: 1031-1050

Heath MR, Gallego A (1997) From the biology of the individual to the dynamics of the population: bridging the gap in fish early life studies. J Fish Biol 51(Suppl A):1-29

Hempel G (1979) Early life history of marine fish - the egg stage. University of Washington Press, Seattle

Huggett JA, Boyd AJ, Hutchings L, Kemp AD (1998) Weekly variability of clupeoid eggs and larvae in the Benguela jet current: implications for recruitment. In: Pillar SC, Moloney CL, Payne AIL, Shillington FA (eds) Benguela dynamics: impacts of variability on shelf-sea environments and their living resources. S Afr J Mar Sci 19:197-210

Hutchings L (1992) Fish harvesting in a variable, productive environment - searching for rules or searching for exceptions? In: Payne AIL, Brink KH, Mann KH, Hilborn R (eds) Benguela trophic functioning. S Afr J Mar Sci 12:297-318

Hutchings L (1994) The Agulhas Bank: a synthesis of available information and a brief comparison with other eastcoast shelf regions. S Afr J Sci 90:179-185

Hutchings L, Boyd AJ (1992) Environmental influences on the purse seine fishery in South Africa. Invest Pesq (Chile) 37 : 23-43 
Hutchings L, Barange M, Bloomer SF, Boyd AJ and 11 others (1998) Multiple factors affecting South African anchovy recruitment in the spawning, transport and nursery areas. In: Pillar SC, Moloney CL, Payne AIL, Shillington FA (eds) Benguela dynamics: impacts of variability on shelf-sea environments and their living resources. S Afr J Mar Sci 19:211-225

King DFP, Robertson AA, Shelton PA (1978) Laboratory observations on the early development of the anchovy Engraulis capensis from the Cape Peninsula. Fish Bull (S Afr) 10:37-45

Korrûbel JL, Bloomer SF, Cochrane KL, Hutchings L, Field JG (1998) Forecasting in South African pelagic fisheries management: the role of expert and decision-support systems. In: Pillar SC, Moloney CL, Payne AIL, Shillington FA (eds) Benguela dynamics: impacts of variability on shelf-sea environments and their living resources. S Afr J Mar Sci 19:415-423

Large WG, McWilliams JC, Doney SC (1994) Oceanic vertical mixing: a review and a model with a nonlocal boundary layer parameterization. Rev Geophys 32:363-403

Lebreton JD, Burnham KP, Clobert J, Andersson DR (1992) Modelling survival and testing biological hypotheses using marked animals: a unified approach with case studies. Ecol Monogr 62:67-118

Letcher BH, Rice JA, Crowder LB, Rose KA (1996) Variability in survival of larval fish: disentangling components with a generalized individual-based model. Can J Fish Aquat Sci 53:787-801

Lluch-Belda D, Crawford RJM, Kawasaki T, MacCall AD, Parrish R H, Schwartzlose RA, Smith PE (1989) Worldwide fluctuations of sardine and anchovy stocks: the regime problem. S Afr J Mar Sci 8:195-205

Lluch-Belda D, Schwartzlose RA, Serra R, Parrish R, Kawasaki T, Hedgecock D, Crawford RJM (1992) Sardine and anchovy regime fluctuations of abundance in four regions of the world oceans: a workshop report. Fish Oceanogr 1:339-347

Lutjeharms JRE, Penven P, Roy C (in press) Shear edge eddies of the southern Agulhas Current. Cont Shelf Res

Marchesiello P, McWilliams JC, Shchepetkin AF (2001) Open boundary condition for long-term integration of regional oceanic models. Ocean Modelling 3:1-21

Melo YC (1994) Spawning frequency of the anchovy (Engraulis capensis). S Afr J Mar Sci 14:321-331

Miller CB, Lynch DR, Carlotti F, Gentleman W, Lewis CVW (1998) Coupling of an individual-based population dynamics model of Calanus finmarchicus to a circulation model for the Georges Bank region. Fish Oceanogr 7: $219-234$

Motos L (1996) Reproductive biology and fecundity of the Bay of Biscay anchovy population (Engraulis encrasicolus L.). Sci Mar 60:195-207

Mullon C, Cury P, Penven P (2002) Evolutionary individualbased model for the recruitment of anchovy (Engraulis capensis) in the southern Benguela. Can J Fish Aquat Sci 59:910-922

Myers RA (1998) When do environment-recruitment correlations work? Rev Fish Biol Fish 8:285-305

Painting SJ, Korrûbel JL (1998) Forecasts of recruitment in South African anchovy from SARP field data using a simple deterministic expert system. In: Pillar SC, Moloney CL, Payne AIL, Shillington FA (eds) Benguela dynamics: impacts of variability on shelf-sea environments and their living resources. S Afr J Mar Sci 19:245-261

Painting SJ, Hutchings L, Huggett JA, Korrubel JL, Richardson AJ, Verheye HM (1998) Environmental and biological monitoring for forecasting anchovy recruitment in the southern Benguela upwelling region. Fish Oceanogr 7: $364-374$

Penven P (2000) A numerical study of the southern Benguela circulation with an application to fish recruitment. $\mathrm{PhD}$ thesis, Université de Bretagne Occidentale, Brest

Penven $\mathrm{P}$, Roy $\mathrm{C}$, Brundrit GB, Colin de Verdière A, Fréon $\mathrm{P}$, Johnson AS, Lutjeharms JRE, Shillington FA (2001a) A regional hydrodynamic model of upwelling in the southern Benguela. S Afr J Sci 97:472-475

Penven P, Lutjeharms JRE, Marchesiello P, Roy C, Weeks SJ (2001b) Generation of cyclonic eddies by the Agulhas Current in the lee of the Agulhas Bank. Geophys Res Lett 27: 1055-1058

Peterson WT, Hutchings L, Huggett JA, Largier JL (1992) Anchovy spawning in relation to the biomass and replenishment of their copepod prey on the western Agulhas Bank. In: Payne AIL, Brink KH, Mann KH, Hilborn R (eds) Benguela trophic functioning. S Afr J Mar Sci 12:487-500

Richardson AJ, Mitchell-Innes BA, Fowler JL, Bloomer SF, Verheye HM, Field JG, Hutchings L, Painting SJ (1998) The effect of sea temperature and food availability on the spawning success of Cape anchovy (Engraulis capensis) in the southern Benguela. In: Pillar SC, Moloney CL, Payne AIL, Shillington FA (eds) Benguela dynamics: impacts of variability on shelf-sea environments and their living resources. S Afr J Mar Sci 19:275-290

Roel BA, Hewitson J, Kerstan S, Hampton I (1994) The role of the Agulhas Bank in the life cycle of pelagic fish. S Afr J Sci 90:185-196

Roy C, Weeks S, Rouault M, Nelson G, Barlow R, van der Lingen CD (2001) Extreme oceanographic events recorded in the Southern Benguela during the 1999-2000 summer season. S Afr J Sci 97:465-471

Schwartzlose RA, Alheit J, Bakun A, Baumgartner TR and 17 others (1999) Worldwide large-scale fluctuations of sardine and anchovy populations. S Afr J Mar Sci 21:89-347

Shackleton LY (1987) A comparative study of fossil fish scales from 3 upwelling regions. In: Payne AIL, Gulland AJ, Brink KH (eds) The Benguela and comparable ecosystems. S Afr J Mar Sci 5:79-85

Shannon LJ, Nelson G, Crawford RJ, Boyd AJ (1996) Possible impacts of environmental change on pelagic fish recruitment: modelling anchovy transport by advective processes in the southern Benguela. Global Change Biol 2: $407-420$

Shchepetkin AF, McWilliams JC (1998) Quasi-monotone advection schemes based on explicit locally adaptive dissipation. Mon Weather Rev 126:1541-1580

Shelton PA (1986) Fish spawning strategies in the variable southern Benguela Current region. PhD thesis, University of Cape Town

Shelton PA, Hutchings L (1982) Transport of anchovy, (Engraulis capensis) Gilchrist, eggs and early larvae by a frontal jet current. J Cons Int Explor Mer 40:185-198

Shelton PA, Hutchings L (1990) Ocean stability and anchovy spawning in the southern Benguela Current region. Fish Bull 88:323-338

Shillington F, Nykjaer L (2002) Environmental conditions and fluctuations in distribution in small pelagic fish stocks (ENVIFISH) 1998-2001. In: Van der Lingen CD, Roy C, Fréon P, Castro L, Gutierrez M, Nykjaer L, Shillington F (eds) Report of GLOBEC-SPACC/IDYLE/ENVIFISH workshop on spatial approaches to the dynamics of coastal pelagic resources and their environment in upwelling areas. GLOBEC Report 16, Plymouth, p 79-80

StatSoft (2000) STATISTICA for Windows. Tulsa, OK 
Stobutzki IC (1998) Interspecific variation in sustained swimming ability of late pelagic stage reef fish from two families (Pomacentridae and Chaetodontidae). Coral Reefs 17: 111-119

Swart VP, Largier JL (1987) Thermal structure of Agulhas Bank water. In: Payne AIL, Gulland AJ, Brink KH (eds) The Benguela and comparable ecosystems. S Afr J Mar Sci 5:243-253

Tyler JA, Rose KA (1994) Individual variability and spatial heterogeneity in fish population models. Rev Fish Biol Fish 4:91-123

van der Lingen CD, Merkle D (1999) Predicting anchovy and sardine recruitment from pelagic pre-recruit surveys. S Afr Shipp News Fish Ind Rev 53(2):24-27

Editorial responsibility: Otto Kinne (Editor), Oldendorf/Luhe, Germany
Verheye HM, Richardson AJ, Hutchings L, Marska G, Gianakouras D (1998) Long-term trends in the abundance of coastal zooplankton in the southern Benguela ecosystem, 1951-1996. In: Pillar SC, Moloney CL, Payne AIL, Shillington FA (eds) Benguela dynamics: impacts of variability on shelf-sea environments and their living resources. S Afr J Mar Sci 19:317-332

Werner FE, Quinlan JA, Lough RL, Lynch DR (2001) Spatiallyexplicit individual based modeling of marine populations: a review of the advances in the 1990s. Sarsia 86:405-410

Whitehead PJP (1990) Engraulididae. In: Quero JC, Hureau JC, Karrer C, Post A, Saldanha L (eds) Checklist of the fishes of the eastern tropical Atlantic (CLOFETA), Vol 1. UNESCO, Paris, p 228-229

Submitted: June 12, 2002; Accepted: October 15, 2002

Proofs received from author(s): February 28, 2003 